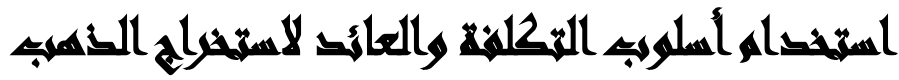

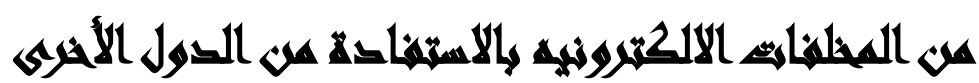

\author{
عماد حمدي عتربس(')- عمرو حسين عبد البر(r)- فؤاد عبد المنعم سعد(r)
}

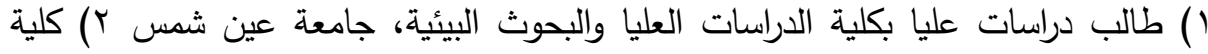
التجارة، جامعة عين شمس ب) هيئة المواد النووية

\section{المستخلص}

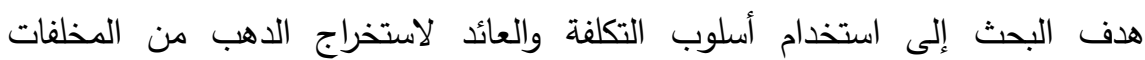

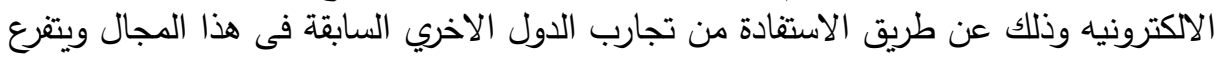

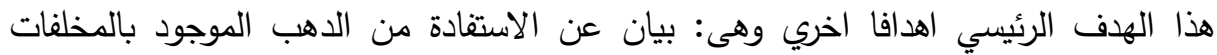

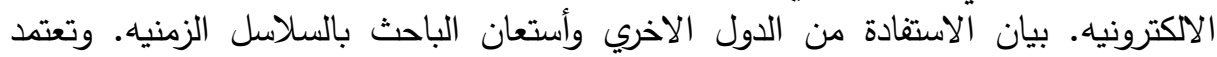

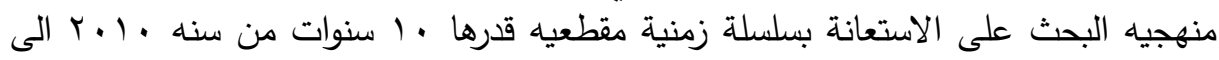

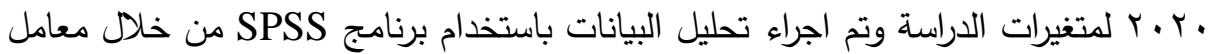

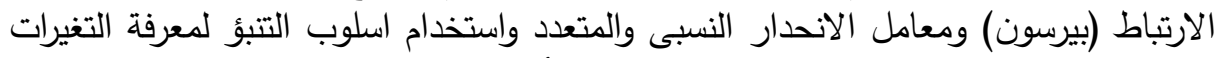

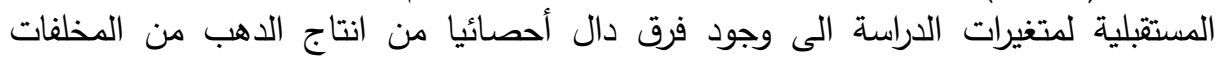

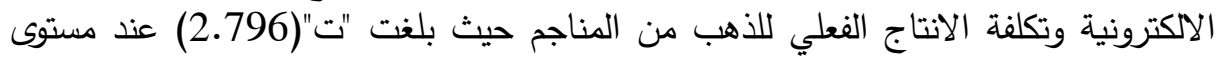

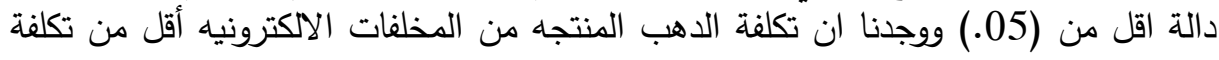

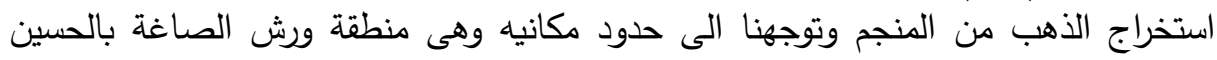

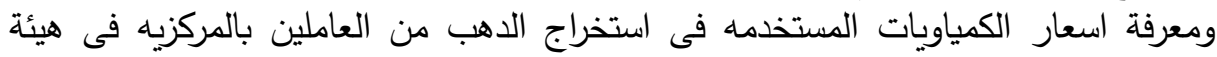

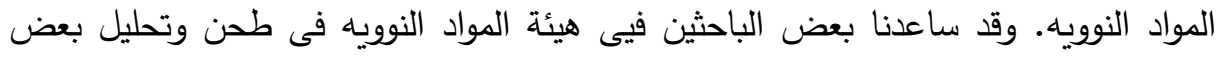

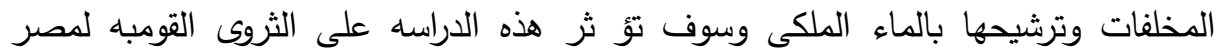

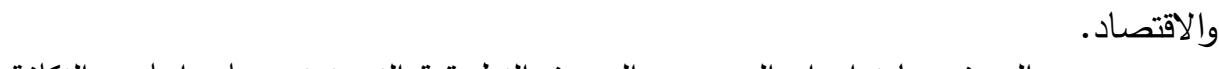
ويوصى البحث بزيادة إجراء المزيد من البحوث التطبيقية التي تعتمد على اسلوب التكلفة

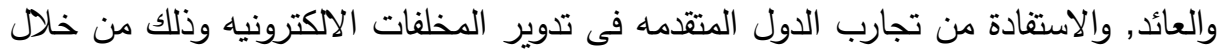
المقالات الحديثة والمؤتمرات

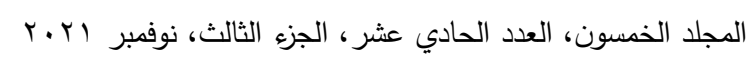

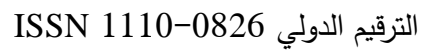
الترقيم الدولي الموحد الإككتروني 3178-2636 


\section{المهيتها}

يزداد استخدامنا للتقنيات الحديثة يوماً بعد يوم، وتحتل تقنية الاتصالات وأنظمة

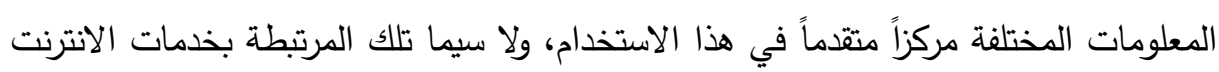
ووسائط الاتصالات والتواصل الاجتماعي، التي استفادت كثيراً من الطفرة المعلوماتية في

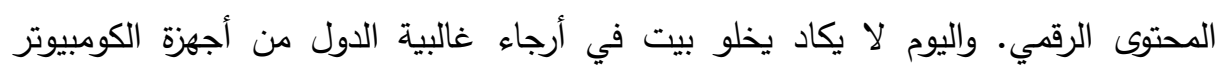

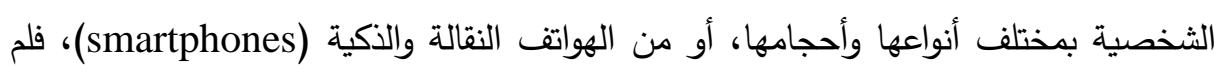

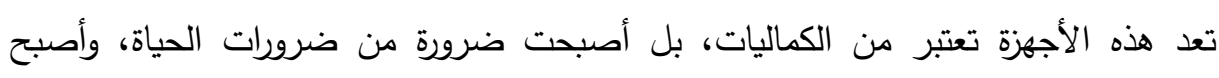

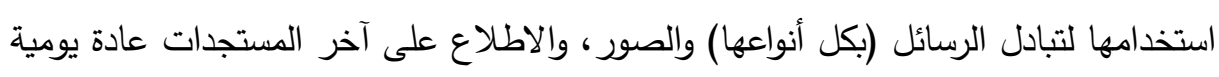

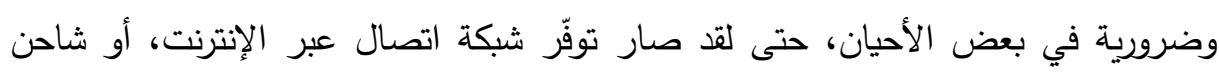

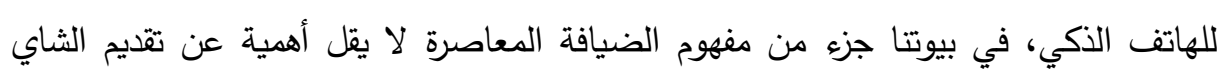

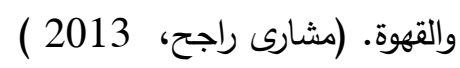

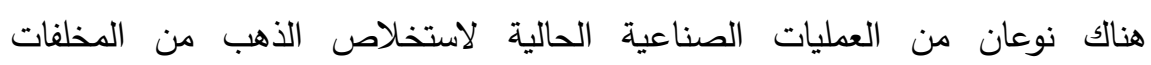
الإكترونية؛ الأول هو حرق تلك الدوائر داخل أفران تحت درجات حرارة عالية، وهي عملية

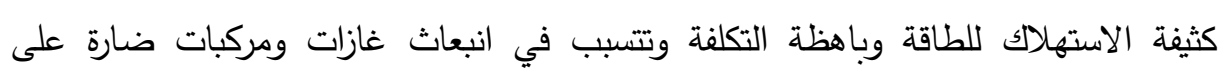

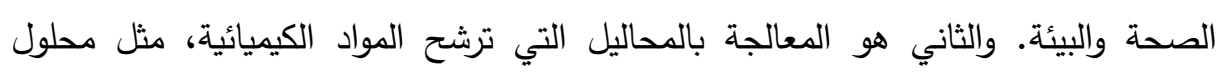

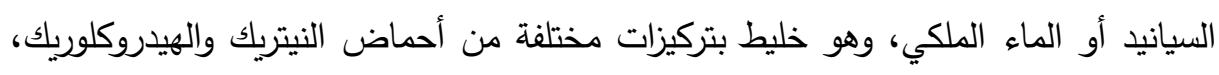
وهو أسلوب مكلّف أيضًا، وقد يتسبب في إحداث سمية عالية للمتعاملين معه. (حسام عطيه،

يتكلف استخراج الذهب من المناجم نحو 9 ا9 دولارًا لكل كيلوجرام في المتوسط، شاملاً

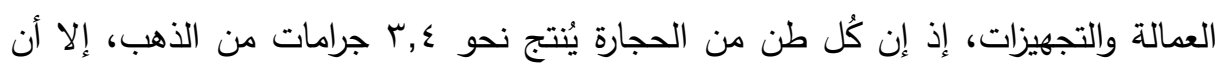

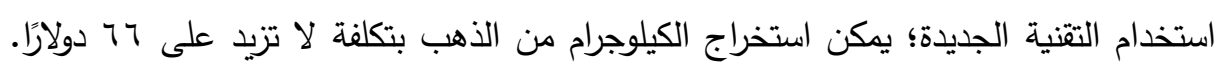

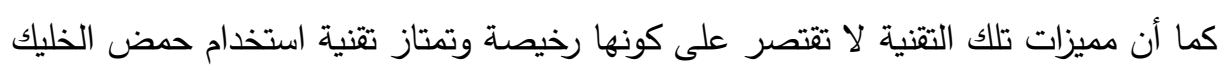
184

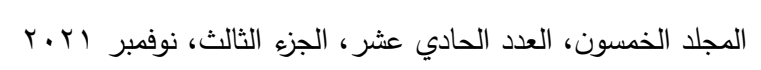

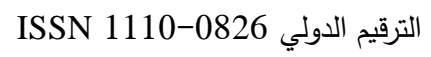

$$
\text { الترقيم الدولي الموحد الإكتروني 3178-2636 الترول }
$$


بالانتقائية لمعدن الذهب دون أن يذيب المعادن الأساسية الأخرى؛ مثل النحاس والنيكل والحديد والكوبالت، والتي عادة ما تكون مصاحبة للذهب داخل الأجزاء الداخلية للأجهزة

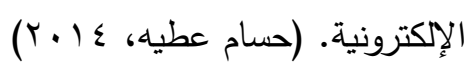

كما أن مميزات تلك التقنية لا تقتصر على كونها رخيصة وتمتاز تقنية استخدام حمض الخليك بالانتقائية لمعدن الذهب دون أن يذيب المعادن الأساسية الأخرى؛ مثل النحاس والنيكل والحديد والكوبالت، والتي عادة ما تكون مصاحبة للذهب داخل الأجزاء الداخلية للأجهزة

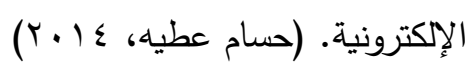

لا يقل البعد البيئي أهمية عن البعدين التتموي والصناعي لتدوير المخلفات الإلكترونية،

إذ إنه ينعكس على حماية الأفراد والبيئة من مخاطر هذه المخلفات، عبر التعامل الآمن معها.

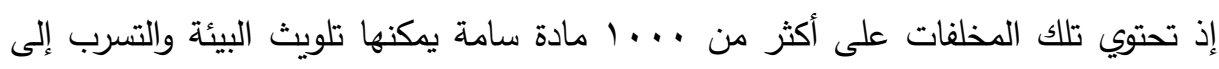

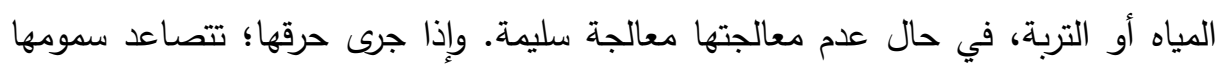
إلى الهواء. ويمكن للمواد العضوية والمعادن الثقيلة الصادرة عن هذه المخلفات أن تظل كامنة التهاه

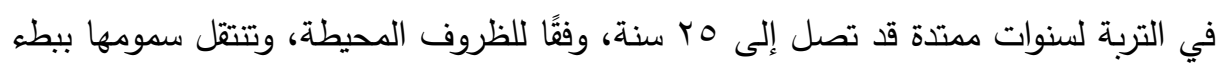

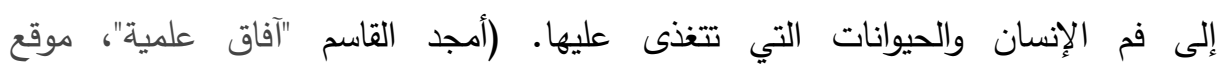
(www.hanan4.wikispaces.com

\section{And I2)}

ان هذه النفايات تعتبر مضرة جدا للبيئة وصحة الانسان نتيجة المواد السامة الموجودة في بنيتها مثل المذيبات المبلورة، ومثبطات اللهب المبرومة، بولي كلوريد الفينيل، والمعادن المان الثقيلة، والمواد البلاستيكية والغازات والرصاص والزئبق والكادميوم. فعلى سبيل المثال، فانه

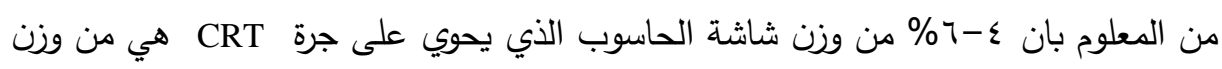
الزئبق الذي تحويه. لذلك فان اعادة تدوير المعادن الثمينة وتخليص الانسان من التأثيرات التي هي هن وني

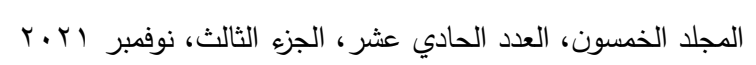

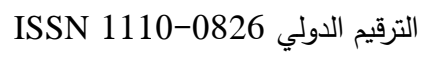

$$
\text { الترقيم الدولي الموحد الإكتروني 3178-2636 الترول }
$$


تضر بصحة الانسان و البيئة واستخدامها مرة اخرى هو أمر مهم من ناحية صحة الانسان

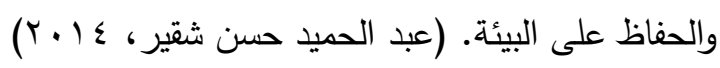

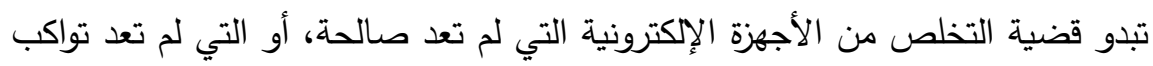

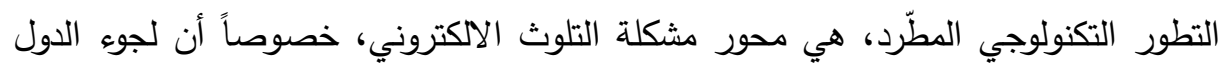

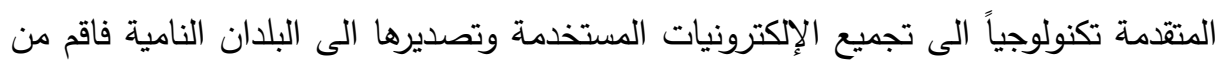

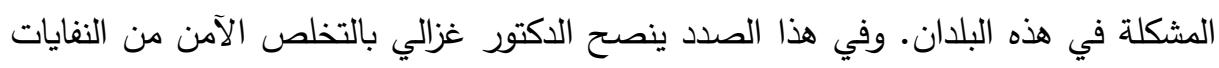

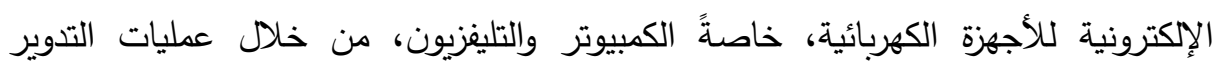

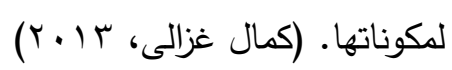

تعتبر مصر من الدول المتقدمة فى مجال إعادة تدوير النفايات الإلكترونية فى الثرق الأوسط، حيث تتتج نحو أكثر من •0 ألف طن سنويا لكن بدون الاستفادة من قيمتها الاقتصادية ويقتصر دور الشركات التى تعمل فى هذا المجال على تجميع وفرز النقان لنفايات

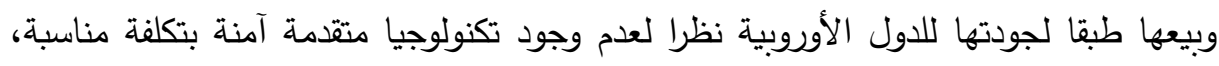
قادرة على تحليل هذه النفايات محليا مما قد ينعش الاقتصاد المصرى ويجعلنا من مصدرى لأنها المعادن الثمينة كالذهب. (داليا عطيه، فادئ 2018).

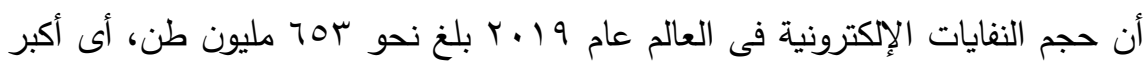

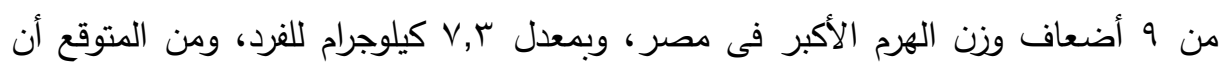

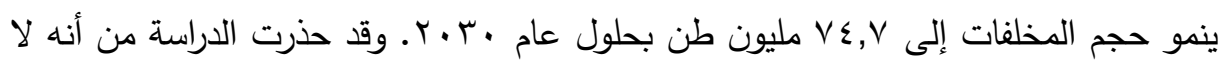

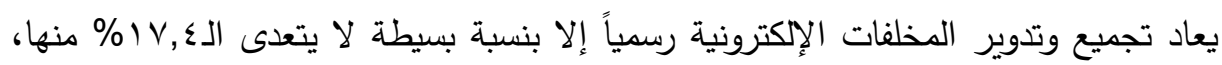

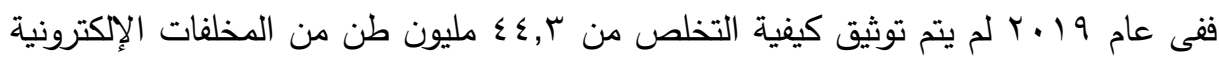

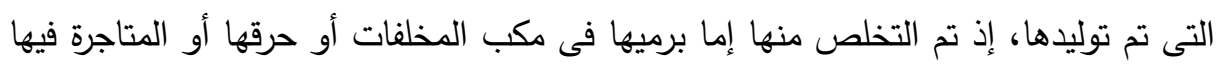

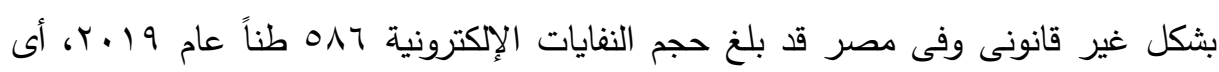




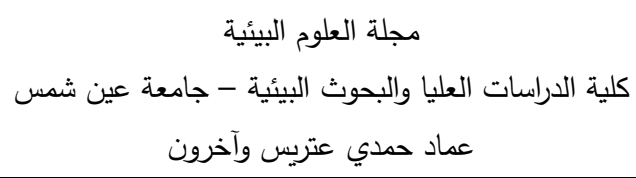

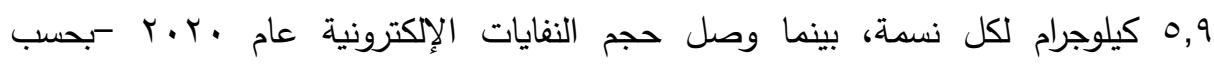

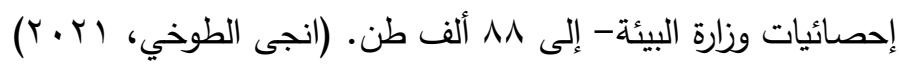

\section{اسمئلا المهيه}

السؤال الرئيسي: ما استخدام اسلوب التكلفة والعائد لاستخراج الدهب من المخلفات

الالكترونية بالاستفادة من تجارب الدول الاخري؟

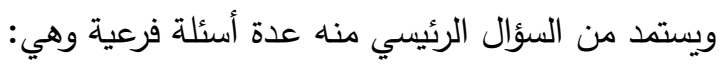

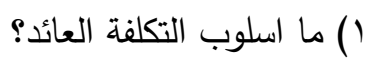

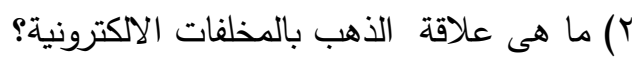

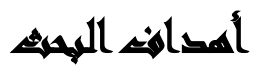

الهاف الرئيسي: استخدام اسلوب التكلفة والعائد لاستخراج الدهب من المخلفات الاكترونية بالاستفادة من تجارب الدول الاخري. • بيان عن التكلفة والعائد. • • • بيان عن الاستفادة من الدهب الموجود بالمخلفات الالكترونية.

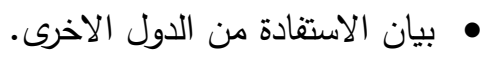

\section{هزوض الهبه}

العلاقة بين استخراج الذهب من المخلفات الاككترونيه ويمكن تخليص هذه العلاقة في فرضين عدم وبديل.

الفرض العدم: لايوجد علاقة بين استخراج الذهب من المخلفات الآكترونية والثروة القومية.

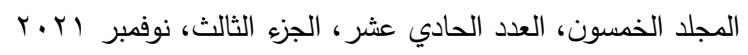

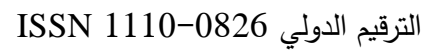

$$
\begin{aligned}
& \text { الترقيم الدولي الموحد الإكتروني 3178-2636 لتربي }
\end{aligned}
$$


الفرض البديل: يوجد علاقة بين استخراج الذهب من المخلفات الاككترونية والثروة القومية.

\section{مبوك المهAم}

$$
\text { الحدود الزمنية: الفترة من سنه } 2000 \text { الى سنه } 2020 \text { الحكانية: هيئة المواد النووية - القاهرة. }
$$

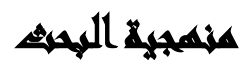

تستمد هذه الدراسة أهميتها من الموضوع ومدى ضرورته في ظل المنافسة خاصة في ظل تجانس المنتجات، بالإضافة إلي تحقيق أهداف البحث فقد إعتمدت الباحثة على المنهـ الإستقرائي والمنهج الإسنباطي وذلك على المانى النحو الآتي: المنهج الإستقرائي: والذي يعتمد على الدراسات الدكتبية والتي تعتمد علي الكتب والدوريات العربية والأجنبية ويتم ذلك من خلال إطار نظري تستخدم فيه مفاهيم التكاليف البيئة وقياسها ومدى علاقتها بالبيئة وكيفية تطورها علي البيئة ومدى تأثيرها على المنشأة الصناعية.

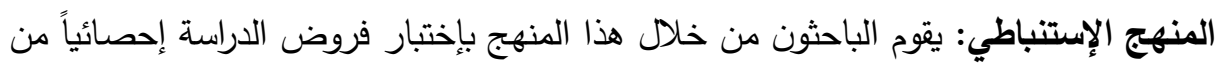
خلال الدراسة الميدانية.

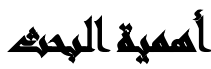

الاستفادة الكبرى من استخراج الذهب من المخلفات الالكترونية ويرجع ذلك الى اهمية

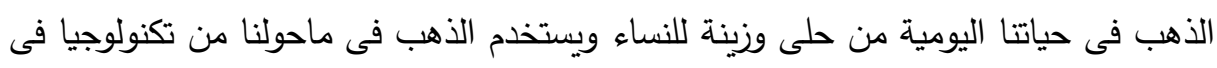

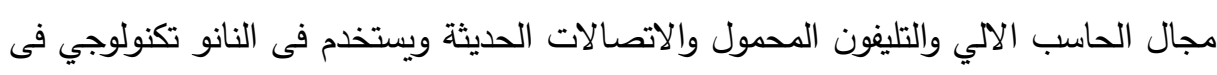
الاجزاء المتناهية الصغر وفى العلاج بالنانو تكنولوجي حيث ان الذهب يتقبله جسم الانسان

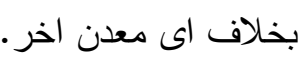


الأهمية العملية:

ا ـ ان هذه الدراسة سوف يكون للهيئة دور فيها من خلال الدراسات والابحاث فى استخلاص الدهب من المخلفات.

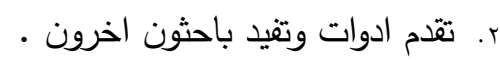
r. هذه الدراسة ستكون اضافة للحياة العملية التى ستشملها نتائج البحث. ع. الحد من الحاجة إلى المواد الخام الجديدة والتخلص من المخلفات والطاقة. ه. خلق نمو اقتصادي جديد وفرص عمل "مراعية للبيئة" وفرص أعمال جديدة. 7. الاستفادة من العائد الكبير من استخراج الدهب من المخلفات الالكترونية.

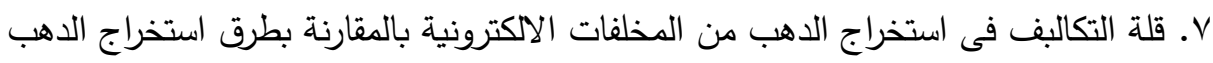
الاخرى.

الجهات المستفيدة: وزارة البترول والتعدين، وزارة البيئة.

\section{السراسايت المايرية}

دراسة (Christian Hagelüken and Christopher W. Corti, 2010) بعنوان: Recycling of gold from electronics: Cost-effective use through 'Design for Recycling.

إعادة تدوير الذهب من الإككترونيات: استخدام فعال من حيث التكلفة من خلال "تصميم لإعادة التدوير •

مع استخدام أكثر من .r طن من الذهب في الإلكترونيات كل عام، توفر المعدات

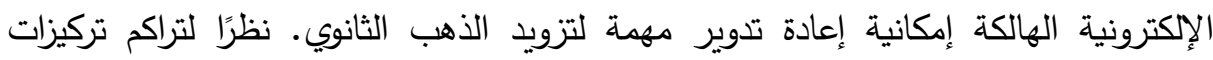

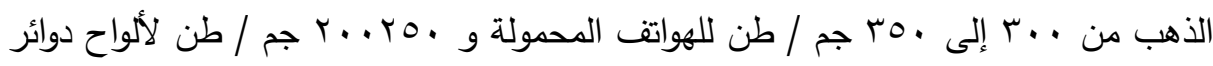

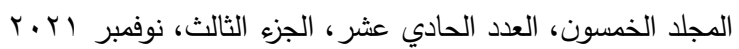

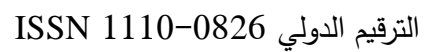

$$
\begin{aligned}
& \text { الترقيم الدولي الموحد الإلكتروني 3178-2636 }
\end{aligned}
$$


الكمبيوتر ، فإن هذا "المنجم الحضري" يكون أكثر ثراءً بشكل كبير مما هو متاح في الخامات

لا تحظى دائمًا بتقدير أهمية المحتوى الذهبي للإلكترونيات الخردة في اقتصاديات

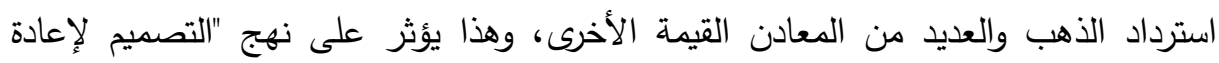

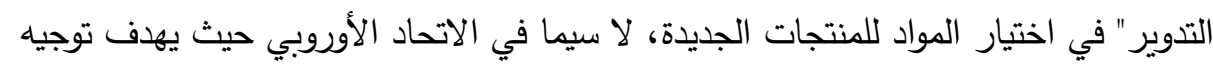
WEEE

$$
\text { المستخدم في التعدين الأولي. }
$$

دراسة (Youssef. Chehade, Ameer. Siddique, 2012 Dubai) بعنوان: Recovery of Gold, Silver, Palladium, and Copper from Waste Printed Circuit Boards

$$
\text { استعادة الذهب والفضة والبلاديوم والنحاس من لوحات الدوائر المطبوعة النفايات. }
$$

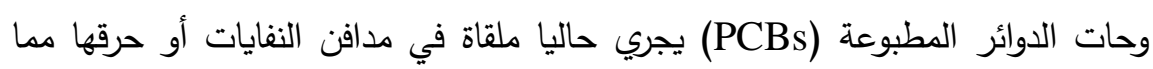

يسبب خطورة الضرر البيئي في شكل غازات سامة أو رشح خطرة مجمعات سكنية. تحتوي

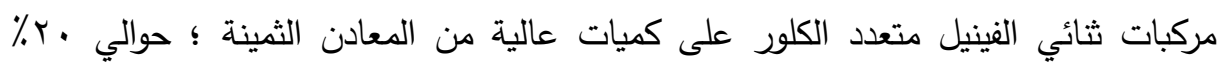

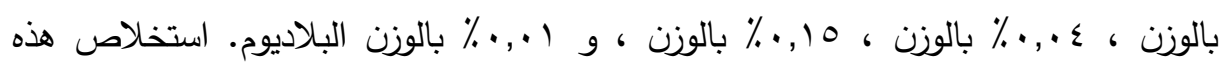

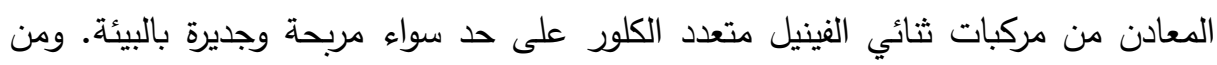
هنا، تهدف هذه الدراسة إلى تصميم عملية تجارية لاستخراج هذه المعادن الأربعة من مركبات

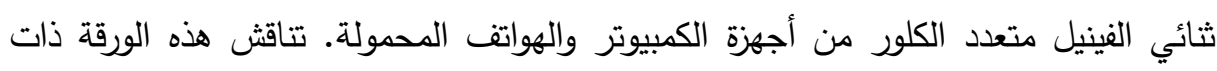

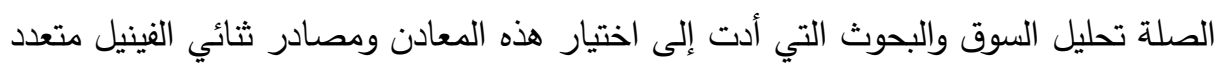
الكلور. علاوة على ذلك ، فإن عملية الاستخراج المقترحة لها تم تقسيمها إلى ثلاث مرأ مراحل:

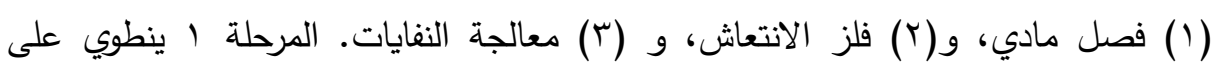

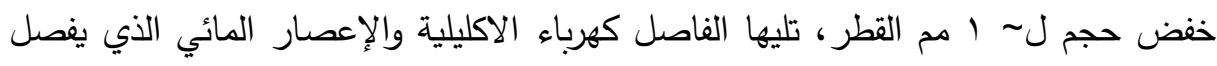

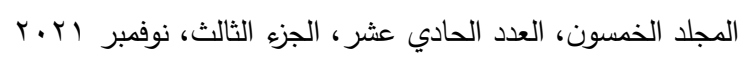

$$
\begin{aligned}
& \text { الترقيم الدولي 0826-0 التئ } \\
& \text { الترقيم الدولي الموحد الإكتروني 3178-2636 }
\end{aligned}
$$




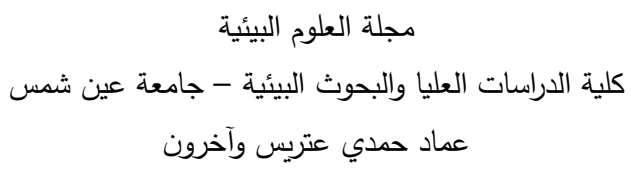

المعادن عن اللافلزات. المرحلة الثانية يفصل بين المعادن المستهدفة الفردية من بعضها البعض من قبل معالجة المياه المعدنية.

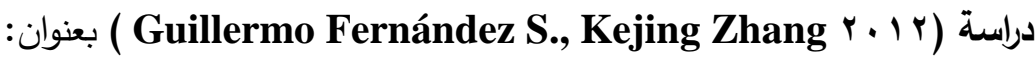
EXTRACTION OF GOLD AND OTHER PRECIOUS METALS FROM E-WASTE.

استخراج الذهب والمعادن الثمينة الأخرى من المخلفات الالكترونيه

E-Waste والإكترونية (EEE) وأجزائه التي تم تجاهلها من قبل المالك كمخلفات دون نية إعادة استخدامها. E-waste هو اسم غير رسمي مشهور للمنتجات الإلكترونية يقترب من نهاية

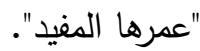

وتعد أجهزة الكمبيوتر والتلفزيون وأجهزة الفيديو وأجهزة الاستريو وآلات التصوير والهواتف

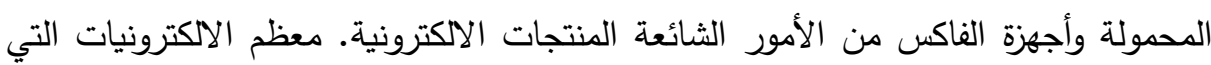

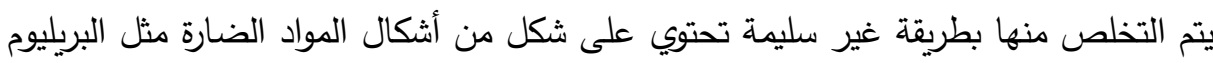
والكادميوم والزئبق والرصاص. هذه المواد قد تكون تتبع العناصر، ولكن عند إضافتها من

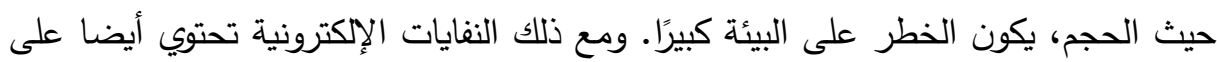
نسبة عادلة من المعادن الثمينة مثل Rh etc ،Pd ،Au ،Ag ،Cu.

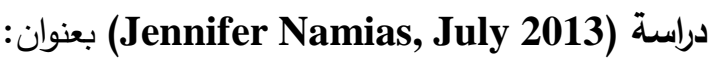
THE FUTURE OF ELECTRONIC WASTE RECYCLING IN THE UNITED STATES. Obstacles and Domestic Solutions. مستقبل إعادة تدوير النفايات الإككترونية في الولايات المتحدة الامريكية: العقبات والحلول

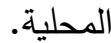

أصبحت الاككترونيات الاستهلاكية جزءا لا يتجزأ من الحياة اليومية وثورة في الطريقة التي نحن التواصل واسترجاع المعلومات والترفيه عن أنفسنا. بين الهواتف المحمولة وأجهزة

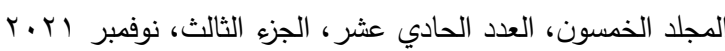

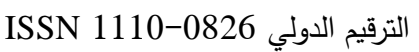

$$
\begin{aligned}
& \text { الترقيم الدولي الموحد الإلكتروني 3178-2636 }
\end{aligned}
$$


الكمبيوتر ، أجهزة التلفزيون ، وأجهز iPad ، والقارئ الإلكتروني ، ويقدر أن الشخص العادي

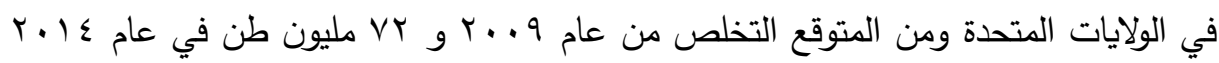
(Ping Jiang et al) شخص/ سنة ا، بينما ينتج سكان الولايات المتحدة حوالي > كيلوغرامات من النفايات الإكترونية / الثخص / السنة r. قد يعزى هذا التناقض إلى التباين تعريفات النفايات الإلكترونية؛ في النفايات الإلكترونية في الولايات المتحدة تتكون عادة من تكنولوجيا

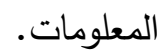

دراسة (P. I. Okwu and I. N. Onyeje, 2014) بعنوان:

Extraction of Valuable Substances from E-Waste.

$$
\text { استخراج المواد القيمة من النفايات الإلكترونية. }
$$

الاستخراج الجانبي الجيد للمواد القيمة عن طريق إعادة التدوير ليتم إخفاء ملايين الدولارات من الذهب والفضة والمعادن الثمينة الأخرى عن مدافن النفايات الإلكترونية لأن الآلات الإككترونية تستخدم الكثير من المعادن الثمينة ويمكن استعادة نفاياتها في عملية تسمى ونى

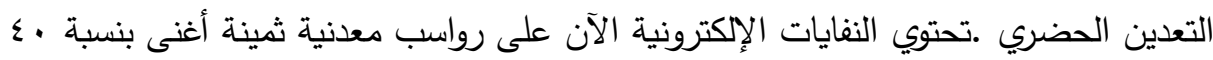
إلى •0 مرة من الخامات المستخرجة من الأرض لعمليات المشاركة في إعادة تدوير النفايات

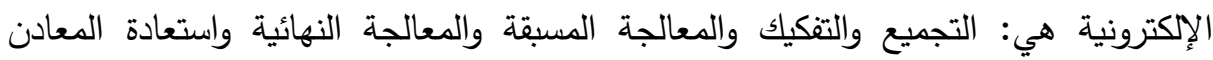
النهائية .لتحقيق الاستدامة البيئية ، فإن الاتجاه في إدارة النفايات الإلكترونية هو الحوسبة الخضراء. دراسة (Sara M. Khalila, Maher A. Mesbahb, 2015) بعنوان: Geological Evolution of Sukari Gold Mines Area- Eastern Desert, Egypt.

$$
\text { التطور الجيولوجي لمنطقة منجم الذهب السكري - الصحراء الثرقية، مصر . }
$$

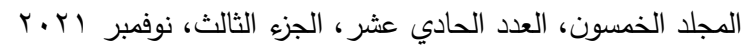

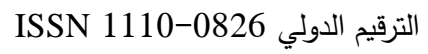

$$
\begin{aligned}
& \text { الترقيم الدولي الموحد الإكتروني 3178-2636 }
\end{aligned}
$$


أصبحت منطقة مناجم الذهب في السكرى الآن موقعًا عالميًا تم استكثافه واستغلاله

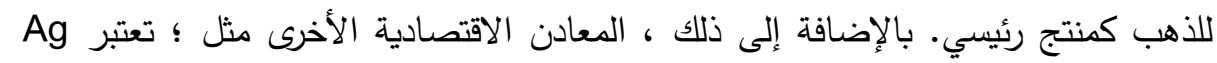

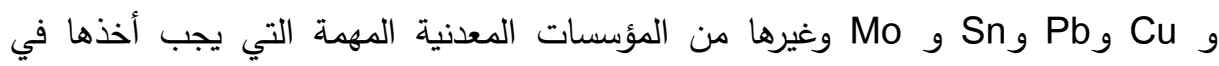
الاعتبار. تمت دراسة الصخور السفلية المختلفة التي تستضيف المعادن في منطقة مناجم

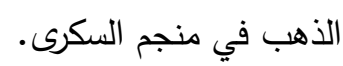

P. Prasanna Natesha, S. Govindaradjaneb, S. Pradeep ) دراسة (Kumarb, 2015

Methodological review on recovery of gold from E-waste in India. مراجعة منهجية لاستعادة الذهب من النفايات الإكترونية في الهند.

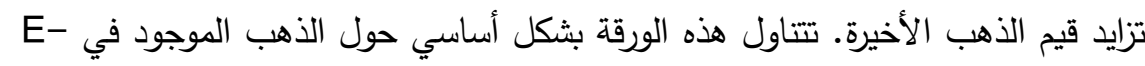
Waste لاسترداد الذهب. يتم تحليل منهجيات مثل تقنيات تعدين المعادن الحرارية والمعادن الحرارية الحيوية ، وكذلك تقييم كفاءة استرداد الذهب من النفايات الإلكترونية. الكلمات الدالة .باستخدام السيانيد. ثم تخضع المادة المرتشحة التي تحتوي على الذهب / الفضة التي تم الحصول عليها

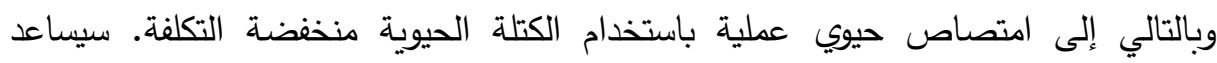
النموذج المقترح من قبلنا.

دراسة (Ngela Cristina Kasper, and Hugo Marcelo Veit, 2018) بعنوان: GOLD RECOVERY FROM PRINTED CIRCUIT BOARDS OF MOBILE PHONES SCRAPS USING A LEACHING SOLUTION ALTERNATIVE TO CYANIDE.

استرداد الذهب من لوحات الدوائر المطبوعة من الهواتف النقالة قصاصات باستخدام محلول الرشح بديلا عن السيانيد.

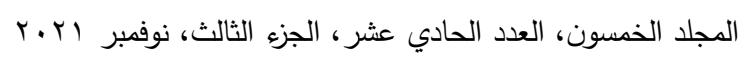

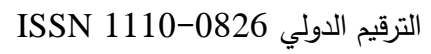

$$
\begin{aligned}
& \text { الترقيم الدولي الموحد الإكتروني 3178-2636 }
\end{aligned}
$$


تجتذب لوحات الدوائر المطبوعة من نفايات المعدات الكهربائية والكترونيه (WEEE) الاهتمام بين الباحثين لأسباب تتعلق بالثواغل البيئية وأساسا لمحتوياتها من المعادن النفيسة مثل الذهب. التالي، تهدف هذه الدراسة إلى توصيف أنواع مختلفين لآنيان من ثنائي الفينيل متعدد الكلور من الهواتف النقالة بالنسبة لكميه الذهب الواردة.

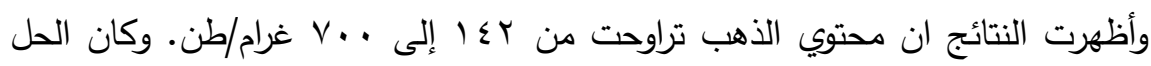

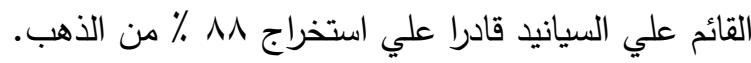
دراسة (Alexander Birich, Bernd Friedrich,2019) بعنوان: Cyanide alternative leaching reagents for gold recovery from electronic waste: Potential and limitations of thiosulfate.

سيانيد الكواشف النضدية البديلة لاستعادة الذهب من النفايات الإكترونية: إمكانات وقيود ثيوكبريتات.

الذهب لديه مقاومة كيميائية ممتازة والتوصيل الكهربائي .هذه الخصائص المميزة تجعلها مادة مفيدة خاصة في الصناعة الإلكترونية. سبب ندرة الذهب ومجال التطبيقات الواسع هو ارتفاع الأسعار وإعطاء دافع اقتصادي لإعادة التدوير .تصبح المقاومة الكيميائية المتميزة للذهب عيبًا عندما يتعلق الأمر بمعادن الذهب .العمليات التطبيقية مثل الزئبق والكلوريد والسيانيد بثكل رئيسي هي في معظمها عدوانية وسامة للغاية .بسبب الآثار البيئية. دراسة (MerveSahan, Mehmet Ali Kucuker, 2019) بعنوان: Determination of Metal Content of Waste Mobile Phones and Estimation of Their Recovery Potential in Turkey.

تحديد محتوى المعادن من الهواتف المحمولة النفايات وتقدير إمكانات الانتعاش في تركيا. تثكل الهواتف المحمولة المستعملة في النفايات واحدة من أسرع أنواع الأجهزة الكهربائية والإكترونية للنفايات (WEEE) نمواً في جميع أنحاء العالم بسبب الابتكارات التكنولوجية

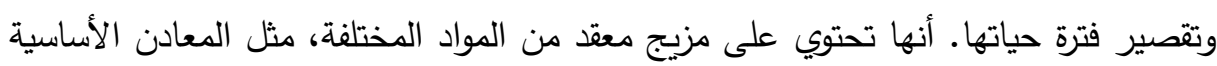
194

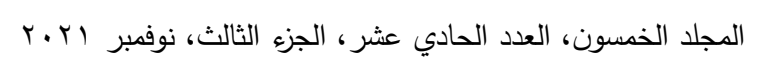

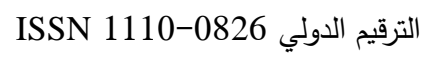
الترقيم الدولي الموحد الإكتروني 3178-2636 
والمعادن الثمينة والعناصر الأرضية النادرة وتمثل مصدرا هاما للمعادن الخام الثانوية. كانت الأهداف الرئيسية لهذه الدراسة توصيف تركيز المعادن للهواتف النقالة المهدورة من خلاد تحسين معايير تشغيل مطياف الانبعاث البصري للبلازما المقترنة بالحث (ICP-OES) وتقدير إمكانات استعادة المعادن للهواتف المحمولة المستعملة. هذه الدراسة على مواصلة أنشطة البحث للحصول على بيانات شاملة لتحديد المعادن الحرجة (المعادن الثمينة والعناصر الأرضية النادرة) في عينات WEEE بحيث يمكن اختيار استراتيجيات إعادة التدوير والاستعادة المناسبة وتتفيذها.

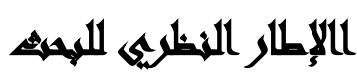

تمهيد: تحتوي الإلكترونيات الحديثة على •ج عنصرًا كيميائيًا مختلفًا بما في ذلك المعادن الأساسية مثل النحاس والقصدير والمعادن الخاصة مثل الإكترونيات الكوبالت والإنديوم والأنتيمون والمعادن النفيسة مثل الفضة والذهب والبلاديوم. على الرغم من أن بعض المض المواد الكيميائية

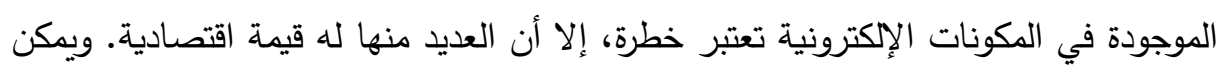

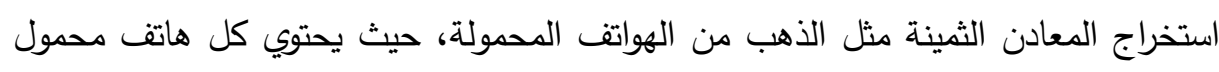

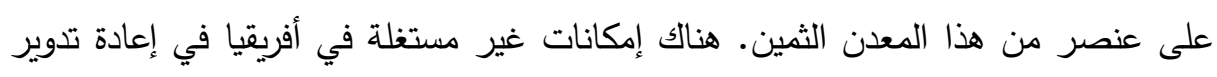
عناصر الهاتف المحمول بهذه الطريقة ، حيث تتمركز معظم المشاريع في البلدان المتقدمة.

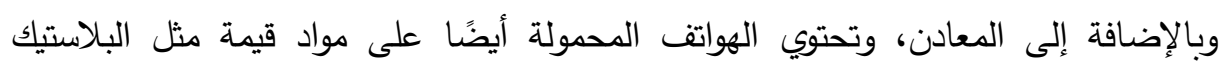
والزجاج والسيراميك. ومع إنشاء اقتصاد دائري، يمكن تحويل مواد النفايات هذه إلى مواد خام إنى إنى

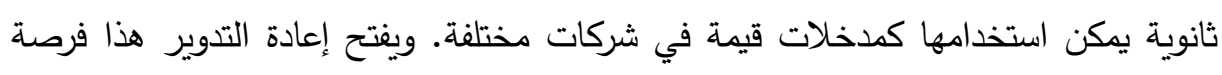

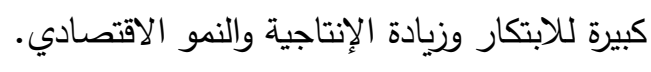

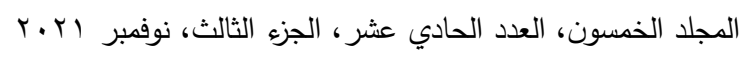

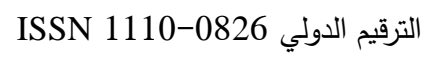

$$
\begin{aligned}
& \text { الترقيم الدولي الموحد الإكتروني 3178-2636 }
\end{aligned}
$$


تعريفات التكلفة: تعتبر محاسبة التكاليف إحدى الركائز الهامة التي تعتمد عليها المحاسبة

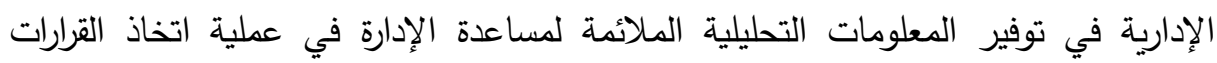

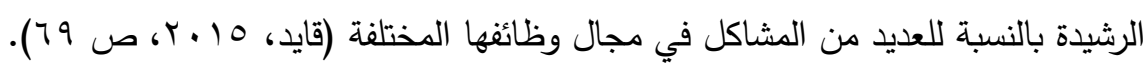

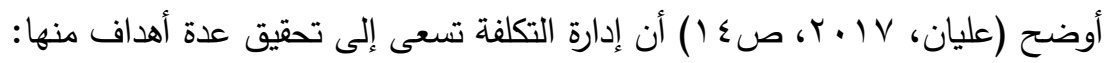
- تتبع وقياس تكاليف الموارد والمستلزمات المستخدمة في أداء الأنثطة المختلفة للتظيم. - تحديد وتجنب حدوث التكاليف غير المضيفة للقيمة، وهي تمثل تكاليف الأنشطة التي يمكن الاستغناء عنها دون التأثير بالسلب على جودة المنتج أو كفاءة الأداء، أو القيمة المضافة للمنتج أو للعميل. - تحديد كفاءة وفعالية كل الأنشطة والعمليات الرئيسية التي يتم مزاولتها والتي تحقق قيمة مضافة للمنظمة والعميل. - تحديد وتقييم الأنشطة الجديدة التي يمكن أن تحس الأداء المستقبلي للمنظمة. خطوات تحليل التكلفة والعائد - - - هدف المشروع وفحص البدائل ذات الصلة - - - ت تحديد التكاليف والعوائد - مياس التكاليف والفوائد استخدام التكلفة والعائد فى معالجة المخلفات الاكترونيه: يقول مؤيدو التجارة أن نمو الوصول إلى الإنترنت هو ارتباط أقوى بالتجارة من الفقر. هايتي فقيرة وأقرب إلى ميناء نيويورك من جنوب شرق آسيا ، ولكن يتم تصدير نفايات إلكترونية أكثر بكثير من نيويورك هئرئ

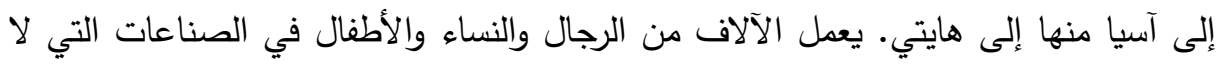
يمكن تحملها في إعادة الاستخدام والتجديد والإصلاح وإعادة التصنيع في تراجع في البلدان المتقدمة. إن حرمان الدول النامية من الوصول إلى الإلكترونيات المستعملة قد يحرمها من

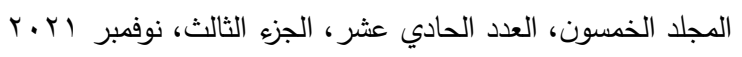

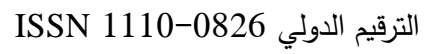
الترقيم الدولي الموحد الإكتروني 3178-2636 
فرص العمل المستدامة والمنتجات بأسعار معقولة والوصول إلى الإنترنت ، أو يجبرها على

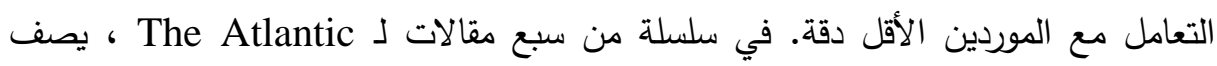

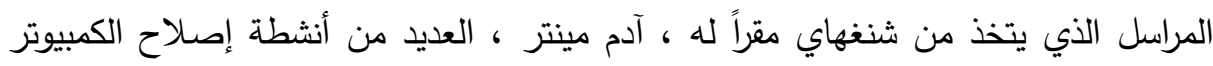

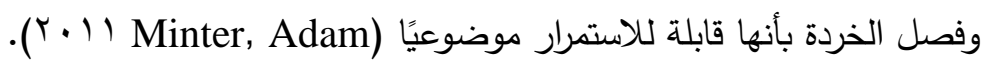
هناك نسبة من المعادن الثمينة الموجودة في مخلفات المعدات الكهبائية والإكترونية يتم فقدانها في معظم عمليات إعادة التدوير الحالية على الرغم من قيمتها الاقتصادية العالية. لذلك فلك فئك ، يجب تطوير وتتفيذ استراتيجيات الإدارة وإعادة التدوير المناسبة للتعامل مع نفايات الأجهزة العنة

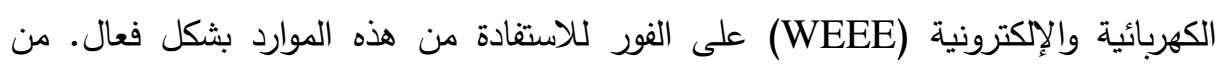
ناحية أخرى، تشتمل الهواتف المحمولة على العديد من السموم التي لا تعد ولا تحصى مثل لهائل

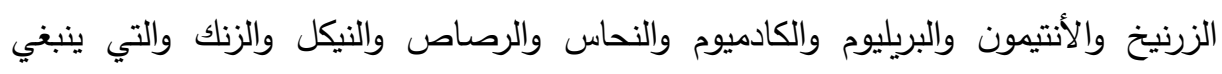
معالجتها واستعادتها بشكل صحيح لتقليل المخاطر المحتملة للمصادر الهواء والتربة والمياه.

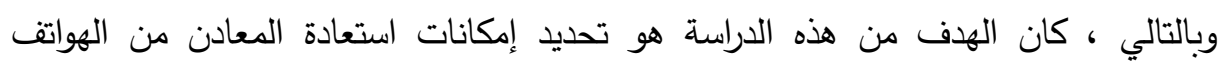

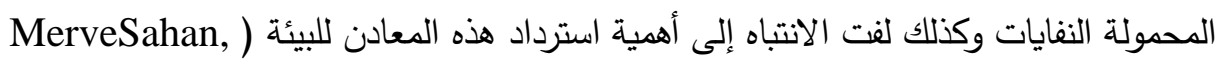
(2019,Mehmet Ali Kucuker أدت عمليات تفكيك النفايات الإكترونية والتخلص منها في البلدان النامية إلى عدد من الآثار البيئية كما هو موضح في الرسم. ينتهي إطلاق الإطلاقات السائلة والجوية في

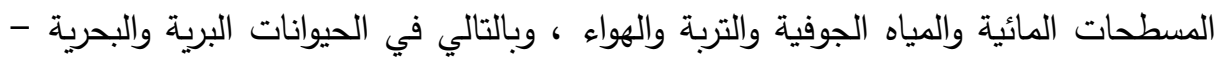

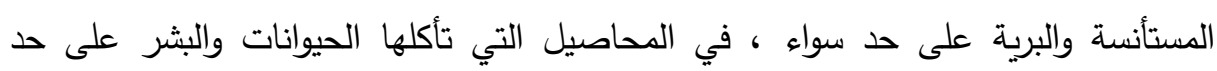
سواء، وفي مياه الشرب (Frazzoli, 2010). يجادل معارضو فائض صادرات الإلكترونيات بأن المعايير البيئية ومعايير العمل المنخفضة والعمالة الرخيصة والقيمة العالية نسبيًا للمواد الخام المستردة تؤدي إلى نقائل نقل أنشطة توليد التلوث ، مثل صهر الأسلاك النحاسية. في الصين وماليزيا والهند وكينيا ودول أفريقية

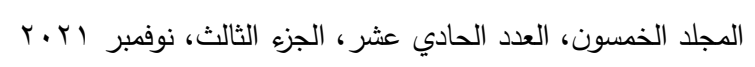

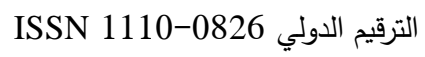

$$
\text { الترقيم الدولي الموحد الإكتروني 3178-2636 }
$$




\section{مجلة العلوم البيئية \\ كلية الدراسات العليا والبحوث البيئية - جامعة عين شمس لبيه \\ عماد حمدي عتريس وآخرون}

مختلفة ، يتم إرسال النفايات الإلكترونية إلى هذه البلدان للدعالجة ، بشكل غير قانوني في

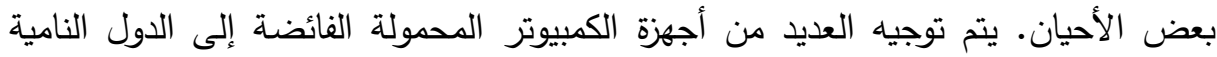

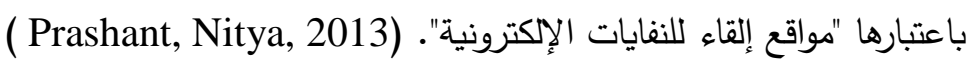

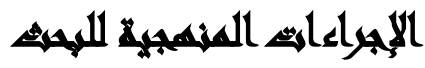

إعتمد الباحثون علي المنهج الإستقرائي الإستتباطي للقراءات والأدبيات للنشاطات الصناعية في اسشتخراج الدهب من المخلفات الالكترونيه، وذلك لمحاولة تحديد أهم المتغيرات للاراسة محور البحث والتي تتؤثر علي المتغير التابع وتحليل حساسية كل متغير بالنسبة لقياس درجة أسلوب تطبيق التكليف علي اساس النشاط الموجه بالوقت علي تدعيم التتافسية على المنثآت الصناعية.

\section{متغيرات الدراسة ودرجة قياسها:}

المتفير المستقل: اسلوب التكلفة والعائد ودرجة قياسه: يوفر العديد من الفرص لتصميم نماذج

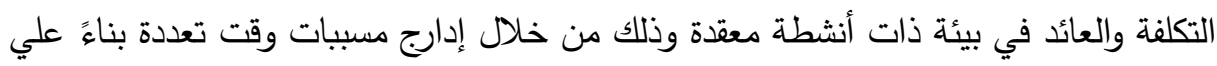
الأنشطة المعقدة دون التوقع في عدد الأنشطة. • المتغير التابع: تكلفة استخراج الدهب من المخلفات الاكترونية ودرجة قياسه: قياس تكلفة الاتئة استخراج الدهب من المخلفات الالكترونيه عن طريق بيرسون بالاستعانة بسلسلة زمنية

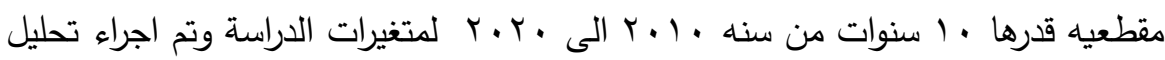
البيانات باستخدام برنامج SPSS من خلال نعامل الارتباط (بيرسون) ومعامل الانحدار

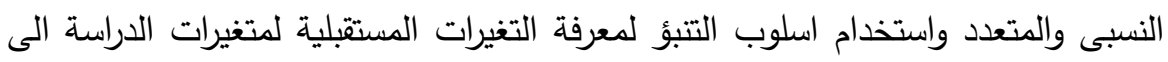

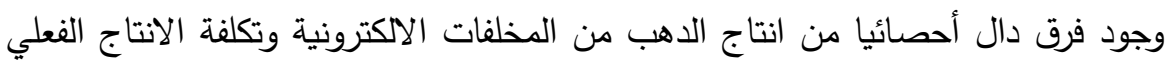

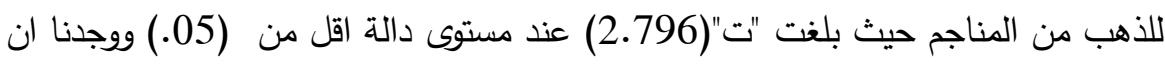
تكلفة الدهب المنتجه من المخلفات الاككترونيه أقل من تكلفة استخراج الذهب من المنجم. 198

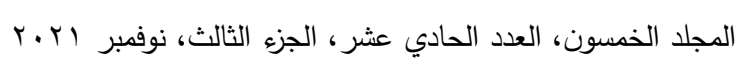

الترقيم الدولي

$$
\text { الترقيم الدولي الموحد الإكتروني 3178-2636 }
$$


الإختبارات الإحصائية المستخدمة: الإختبارات الإحصائية تضمنت:

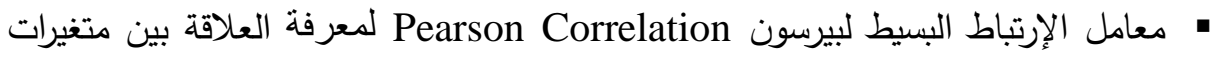

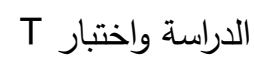
تحليل الإندار البسيط و المتعدد المتدرج لمعرفة آثز المتغيرات المستقلة على المتغير

$$
\text { التابع وللتحقق من صحة فروض الإن الدراسة. }
$$

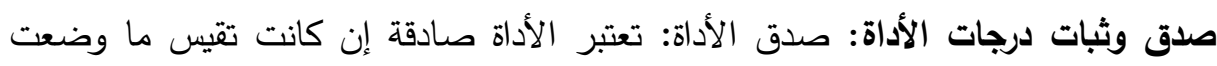

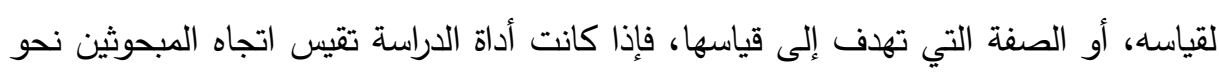

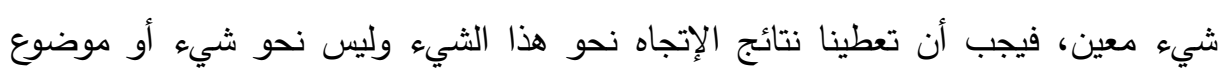
آخر. الثبات: معنى ثبات الإختبار أن يكون الإختبار مماثلاً لنفسه بمعنى أن يعطى نفس النتائج

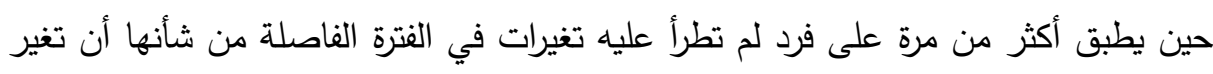

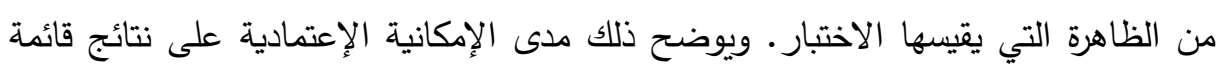
الإنتبيان، ومدى إمكانية تعميم نتائجها على مجتمع الدراسة.

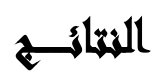

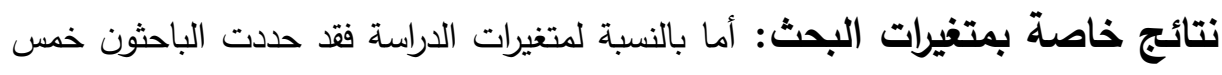

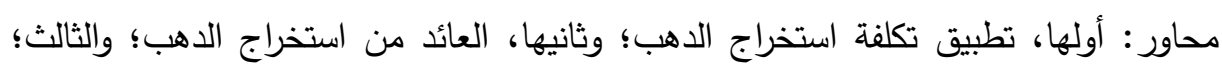

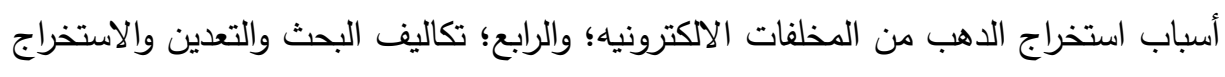

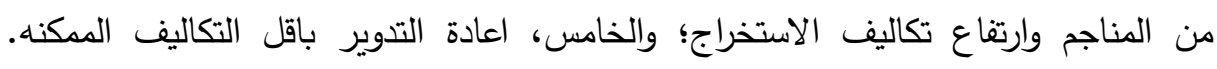

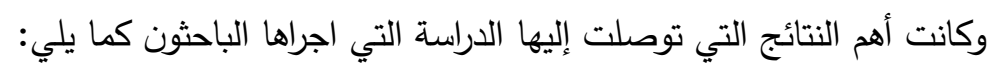

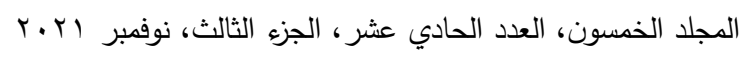

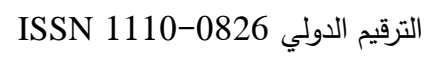

$$
\begin{aligned}
& \text { الترقيم الدولي الموحد الإككتروني 3178-2636 }
\end{aligned}
$$




$$
\begin{aligned}
& \text { مجلة العلوم البيئية } \\
& \text { كلية الدراسات العليا والبحوث البيئية - جامعة عين شمس البية } \\
& \text { عماد حمدي عتريس وآخرون }
\end{aligned}
$$

نتائج خاصة باستخدام اسلوب التكلفة والعائد في استخراج الدهب من المخلفات الالكترونية

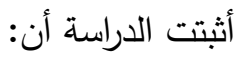

1- يجب دراسة اسلوب التكلفة والعائد التي تساعد على تقليل التكاليف من الإلتزامات

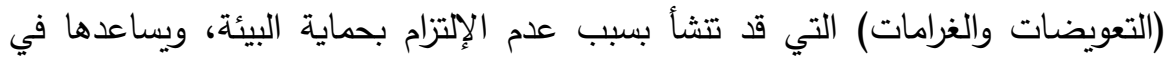
توفير المعلومات اللازمة تكاليف استخراج الدهب من المخلفات الالكترونيه.

r-اسلوب التكلفة والعائد جزء من نظام الإدارة البيئية لأنها أداة أساسية لقياس الأداء البيئي من اجل مساعدة وترشيد نظام الإدارة البيئية.

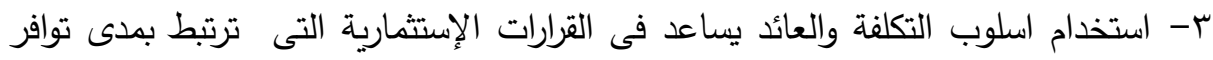

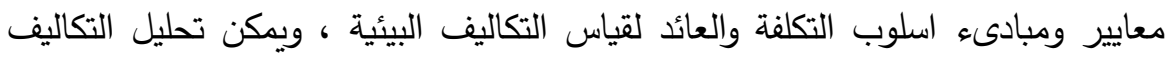
البيئية المستخدمه في استخراج الدهب من المخلفات الالكترونيه عند اتخاذ القرارت الإستثمارية.

نتائج خاصة بصحة فروض الدراسة: قامت الدراسة على فرضين رئيسيين حيث أثبتت

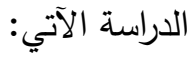


جدول (1): الفرق بين تكلفة الذهب المستخرج من المنجم وتكلفة الذهب المستخرج من المخلفات الالكترونية المتمثلة في قطع متتوعة من اجزاء الكمبيوتر لكنة

\begin{tabular}{|c|c|c|c|c|c|c|}
\hline مستوى الدلالة & قيمة ت & المنجم" تكلفة & الملفة الذهب & 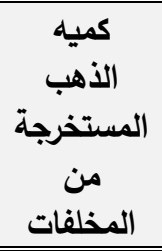 & الكمية & النوع \\
\hline \multirow{11}{*}{$7 \cdot, \cdot r$} & \multirow{11}{*}{2.796} & 9696.27 & 1120.00 & $28.35 \mathrm{~g}$ & kr4. & Ram \\
\hline & & 6895.12 & 440.00 & $16 \mathrm{~g} ، 20$ & $1 \mathrm{k}$ & SMD LED \\
\hline & & 3420.20 & 390.00 & $10 \mathrm{~g}$ & $1 \mathrm{k}$ & IC chips MOBI \\
\hline & & 2052.12 & 440.00 & $6 \mathrm{~g}$ & $1 \mathrm{k}$ & IC chips GPU \\
\hline & & 1026.06 & 340.00 & $3 \mathrm{~g}$ & $1 \mathrm{k}$ & ic chips \\
\hline & & 513.03 & 110.00 & $1.5 \mathrm{~g}$ & $100 \mathrm{~g}$ & SIM CARDS \\
\hline & & 1265.47 & 390.00 & $3.7 \mathrm{~g}$ & $1 \mathrm{k}$ & $\begin{array}{c}\text { ، PCI‘DE } \\
\text { ISA ‘AGP }\end{array}$ \\
\hline & & 2394.14 & 390.00 & $7 \mathrm{~g}$ & $1 \mathrm{k} . \mathrm{g}$ & $\begin{array}{c}\text { ntel 1702A } \\
\text { EPROM }\end{array}$ \\
\hline & & 27262.41 & . & $g \vee q, \vee 1$ & $k) 1 \cdot, 7$ & الاجمالي \\
\hline & & 3407.80 & . 20 Y, 0. & 99,97 & $k \backslash r, \wedge$ & المتوسط \\
\hline & & 3234.05 & $2 \curlyvee \wedge 9, \vee$ & g9, ¿7 & $k r \varepsilon, \wedge$ & الانحراف المعياري \\
\hline
\end{tabular}

(المصدر : من مخرجات برنامج Spss)

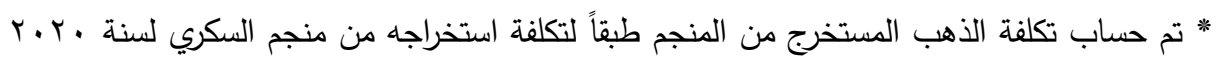

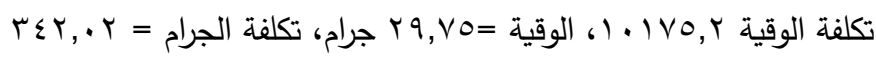

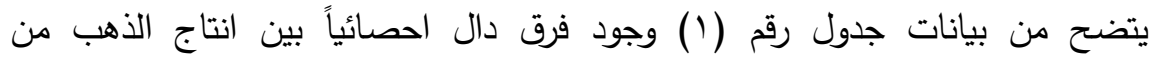

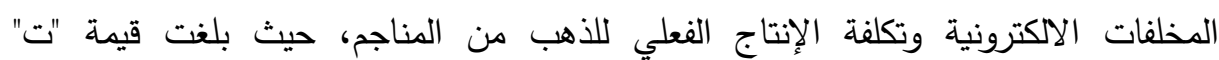

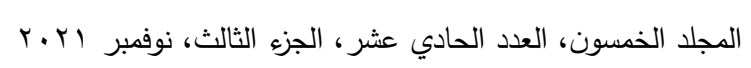

الترقيم الدولي 0826- ISSN 1110

الترقيم الدولي الموحد الإككتروني 3178-2636 


$$
\begin{aligned}
& \text { مجلة العلوم البيئية } \\
& \text { كلية الدراسات العليا والبحوث البيئية - جامعة عين شمس لبه } \\
& \text { عماد حمدي عتريس وآخرون }
\end{aligned}
$$

(Y,Y9 ) عند مستوى دلالة أقل من (0., •))، فنجد ان تكلفة الذهب المنتجة من المخلفات الالكترونية أقل من تكلفة استخراج الذهب من المنجم.

\begin{tabular}{|c|c|c|c|c|c|c|}
\hline 予 & :9 & المنجم & المستخرج من التهلفة المخلفات & المستخرجة الذهب من & المخلفات & من اجزاء الحاسوب الاكترونية \\
\hline \multirow{17}{*}{$\frac{\infty}{\infty}$} & \multirow{17}{*}{ ๙े. } & 684.04 & 340 & $2.00 \mathrm{~g}$ & 1. & Intel $486+\mathrm{DX} 2$ \\
\hline & & 649.84 & 340 & $1.90 \mathrm{~g}$ & 1. & Intel 486 DX4 \\
\hline & & 410.42 & 540 & $1.20 \mathrm{~g}$ & 1. & Intel Pentium \& MMX \\
\hline & & 410.42 & 340 & $1.20 \mathrm{~g}$ & 1. & Intel I960 \\
\hline & & 342.02 & 440 & $1.00 \mathrm{~g}$ & 1. & Intel 486SX \\
\hline & & 410.42 & 340 & $1.20 \mathrm{~g}$ & 1. & i486 TX 486DLC \\
\hline & & 171.01 & 390 & $.50 \mathrm{~g}$ & 1. & $\begin{array}{c}\text { Intel Pentium } 1 \mathrm{MMX} \\
\text { - black fibre }\end{array}$ \\
\hline & & 171.01 & 390 & $.50 \mathrm{~g}$ & 1. & Celeron - black fibre \\
\hline & & 171.01 & 390 & $.50 \mathrm{~g}$ & 1. & Celeron - green fibre \\
\hline & & 171.01 & 390 & $.50 \mathrm{~g}$ & 1. & Celeron - slot one \\
\hline & & 171.01 & 390 & $.50 \mathrm{~g}$ & 1. & Pentium 2 - slot one \\
\hline & & 171.01 & 390 & $.50 \mathrm{~g}$ & 1. & Pentium 3 - slot one \\
\hline & & 171.01 & 390 & $.50 \mathrm{~g}$ & 1. & Pentium 3 \\
\hline & & 171.01 & 540 & $.50 \mathrm{~g}$ & 1. & Pentium 4 \\
\hline & & 4275.25 & 5410.00 & $12.50 \mathrm{~g}$ & $1 \leq$. & الاجمالي \\
\hline & & 305.38 & 386.43 & $0.89 \mathrm{~g}$ & 1. & المتوسط \\
\hline & & 184.47 & 53.58 & $0.54 \mathrm{~g}$ & $\cdot, \cdots$ & الانحراف المعياري \\
\hline
\end{tabular}
جدول (ץ): الفرق بين تكلفة الذهب المستخرج من المنجم وتكلفة الذهب المستخرج من كل من

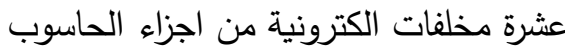

(المصدر : من مخرجات برنامج (Spss)

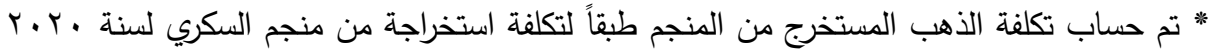

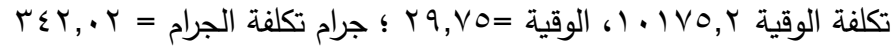

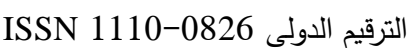
الترقيم الدولي الموحد الإلكتروني 3178-2636 


\section{مجلة العلوم البيئية - ملية \\ كلية الدراسات العليا والبحوث البيئية - جامعة عين شس البية \\ عماد حمدي عتريس وآخرون}

يتضح من بيانات جدول رقم (Y) عدم وجود فرق دال احصائياً بين انتاج الذهب من المخلفات

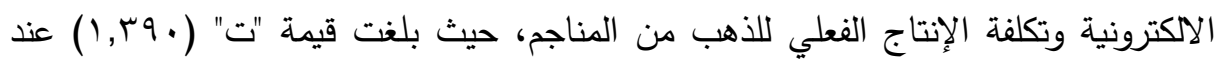

$$
\text { مستوى دلالة (0. • • (•) }
$$

قبول الفرض البديل: القرار: صحة فرض الدراسة القائل: توجد فروق ذات دلالة احصائية عند استخدام المخلفات الالكترونية في صناعة الذهب تتعكس على التكاليف.

\section{الميوكياتص}

في ضوء نتائج الدراسة يوصي الباحثون بما يلي: ا. ضرورة توعية الجمهور سواء اعلاميا او بجميع المجالات من حيث اهميه اعادة تدوير المخلفات الالكترونيه ومما ينتج عن ذلك عائد مربح ومما يودى الى قلة تكاليف التدوير بدلا مما تتسبب هذه المخلفات من اضرار بيئية خطيرة من الاحراق او الدفن، وذلك ئك

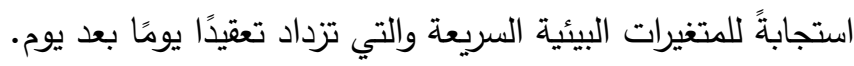

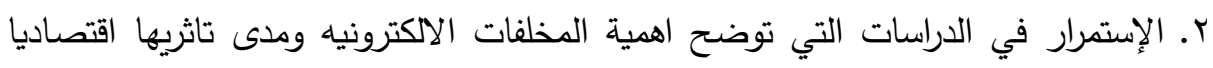

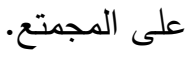
r. زيادة إجراء المزيد من البحوث التطبيقية التي تعتمد على اسلوب التكلفة والعائد فى استخراج الذهب من المخلفات الالكترونيه.

ع. الاستفادة من تجارب الدول المتقدمه فى تدوير المخلفات الالكترونيه وذلك من خلال

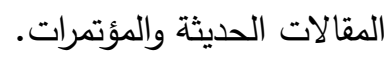

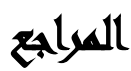

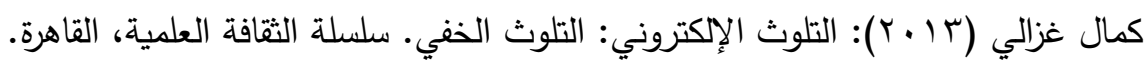

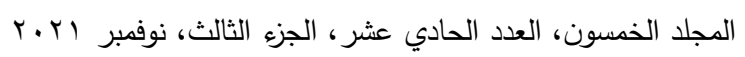

الترقيم الدولي 0826-0 تصدي

$$
\text { الترقيم الدولي الموحد الإكتروني 3178-2636 }
$$




$$
\begin{aligned}
& \text { مجلة العلوم البيئية } \\
& \text { كلية الدراسات العليا والبحوث البيئية - جامعة عين شمس لعس } \\
& \text { عماد حمدي عتريس وآخرون }
\end{aligned}
$$

أمجد قاسم، "آفاق علمية"، موقع www.hanan4.wikispaces.com.

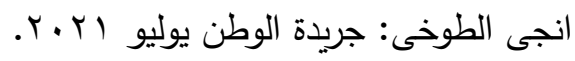

توني، عاصم عبد القادر نصر : تحليل التكلفة - العائد لبرامج التعليم عن بعد المعتمدة على الإتى

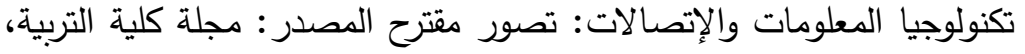

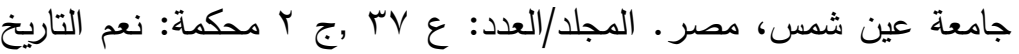

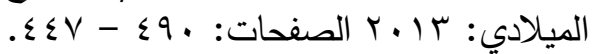

حسام عطية: النفايات الإككترونية: قنابل صامته تعيش بينتا. صحيفة الدستور، إبريل $. p^{\top}+1 \leq$

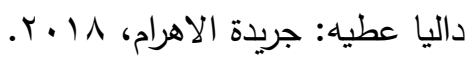

عبد الحميد حسن شقير : النفايات الالكترونية ومخاطرها على الصحة والبيئة. مجلة الكويت،

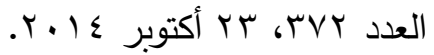

مشاري الراجح: بيوتتا الرقمية. الاقتصادية، يناير س ا • r.

Christian Hagelüken and Christopher W Corti: Recycling of gold from electronics: Cost-effective use through 'Design for Recycling, Vol. 43 No. 3, 2010.

Ngela Cristina Kasper and Hugo Marcelo Veit: GOLD RECOVERY FROM PRINTED CIRCUIT BOARDS OF MOBILE PHONES SCRAPS USING A LEACHING SOLUTION ALTERNATIVE TO CYANIDE. Brazilian Journal of Chemical Engineering, Vol. 35, No. 03, pp. 931-942, July - September, 2018.

Minter, Adam (2011): "Shanghai Scrap" Wasted 7/7. The Atlantic. Retrieved 7 March.

P. I. Okwu and I. N. Onyeje: Extraction of Valuable Substances from E-Waste , American Journal of Engineering Research.

$$
\begin{aligned}
& \text { المجلد الخمسون، العدد الحادي عشر، الجزء الثالث، نوفمبر اب.r. } \\
& \text { الترقيم الدولي 0826-08S 1110 } \\
& \text { الترقيم الدولي الموحد الإكتروني 3178-2636 }
\end{aligned}
$$




$$
\begin{aligned}
& \text { مجلة العلوم البيئية } \\
& \text { كلية الدراسات العليا والبحوث البيئية - جامعة عين شمس لكس } \\
& \text { عماد حمدي عتريس وآخرون }
\end{aligned}
$$

Reshma L. Patel: The Recovery of Precious and Base Metals from EWaste: A Review International Journal of Constructive Research in Civil Engineering (IJCRCE) Vol. 2, Iss. 5, 2016, PP 1.

Alexander Birich and Bernd Friedrich (2019): Cyanide alternative leaching reagents for gold recovery from electronic waste: Potential and limitations of thiosulfate, Alexander Birich, Bernd Friedrich RWTH Aachen University, Proceedings of EMC.

Jennifer Namias (2013): THE FUTURE OF ELECTRONIC WASTE RECYCLING IN THEUNITED STATES:Obstacles and Domestic Solutions Jennifer Namias, July, Columbia University.

MerveSahan, Mehmet Ali Kucuker; BurakDemirel; Kerstin Kuchta and Andrew Hursthouse: Determination of Metal Content of Waste Mobile Phones and Estimation of Their Recovery Potential in Turkey, International Journal of Environmental Research and Public Health - Open Access Journal , 22 January 2019; Accepted: 27 February 2019; Published: 11 March 2019.

P. Prasanna Natesha; S. Govindaradjaneb; S. Pradeep Kumarb: Methodological review on recovery of gold from E-waste in India, Journal of Chemical and Pharmaceutical Sciences ISSN: 0974-2115,JCPS Vol. 8 Iss.2, April-June 2015.

Sara M. Khalil; Maher A. Mesbah; Farouk A. Soliman; Ismail M. Abdul Khalek: Geological Evolution of Sukari Gold Mines Area- Eastern Desert, Egypt, Journal of Petroleum and Mining Engineering 17(1)2015 Volume-03, Issue-01, pp299-304,2014.

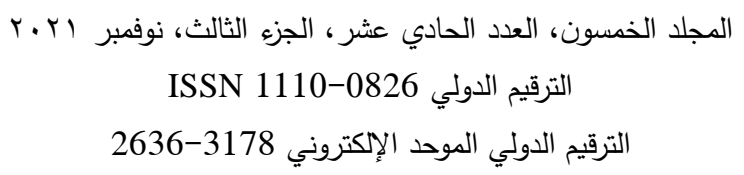




$$
\begin{aligned}
& \text { مجلة العلوم البيئية } \\
& \text { كلية الدراسات العليا والبحوث البيئية - جامعة عين شمس لكس } \\
& \text { عماد حمدي عتريس وآخرون }
\end{aligned}
$$

Youssef. Chehade, Ameer. Siddique, Hisham. Alayan, Naveena. Sadasivam, Saeed. Nusri, and Taleb. Ibrahim: Recovery of Gold, Silver, Palladium, andCopper from Waste Printed Circuit Boards, International Conference on Chemical, Civil and Environment engineering, March 24-25, 2012, Dubai.

Prashant, Nitya (20 August 2008): "Cash For Laptops Offers 'Green' Solution for Broken orOutdatedComputers".Green Technology.Norwalk,Connecticut:Technology Marketing Corporation. Retrieved 17 March 2009. European Centre for Research, Training and Development UK. December, 2013.

Erve Sahan; Mehmet Ali Kucuker; Burak Demirel; Kerstin Kuchta and Andrew Hursthouse: Determination of Metal Content of Waste Mobile Phones and Estimation of Their Recovery Potential in Turkey, 11 March 2019.

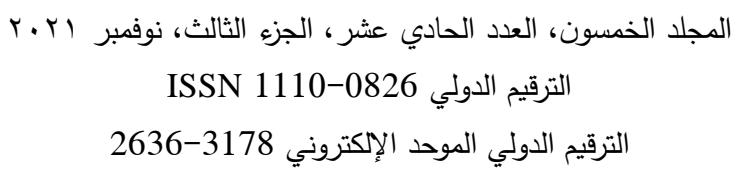




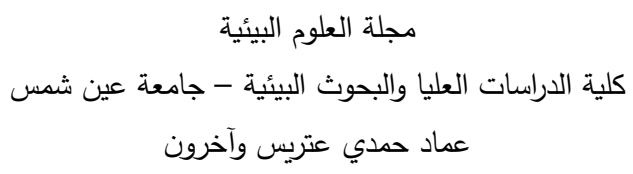

\title{
USING THE COST-BENEFIT METHOD TO \\ EXTRACT GOLD FROM ELECTRONIC WASTE BY TAKING ADVANTAGE OF OTHER COUNTRIES
}

\author{
Emad H. Atrees ${ }^{(1)}$; Amr H. Abdel Bar ${ }^{(2)}$ and Fo'ad A. Saad ${ }^{(3)}$
}

1) Post graduate Student at Faculty of Post-Graduate Studies and Environmental Research 2) Faculty of Commerce, Ain Shams University 3) Authority of Nuclear Materials

\begin{abstract}
This study aimed to use the cost-benefit method to extract gold from electronic waste, by benefiting from the previous experiences of other countries in this field. A statement on the use of gold for electronic waste. Statement of benefit from other countries. The research methodology depends on the use of a 10-year cross-sectional time series from 2010 to 2020 for the study variables. Data analysis was conducted using the spss program through the correlation coefficient (Pearson) and the relative and multiple regression coefficient and the use of the prediction method to know future changes of the study variables to the presence of a statistically significant difference from the production Gold from electronic waste and the actual production cost of gold from mines, which amounted to " $T$ " $(2.796)$ at a function level less than (.05) We found that the cost of gold produced from electronic waste is less than the cost of extracting gold from the mine. Some wastes are filtered with royal water and this study will affect the national wealth of Egypt and the economy. The research recommends conducting more applied research that depends on the cost-benefit method. And benefits from the experiences of developed countries in recycling electronic waste, through recent articles and conferences.
\end{abstract}

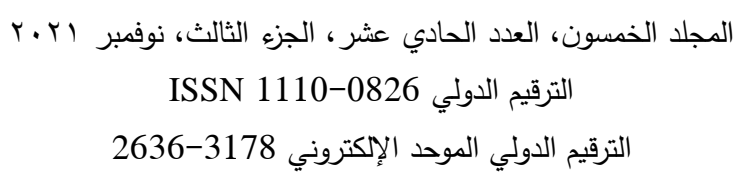

